(2) Open Access Full Text Article

LETTER

\title{
Asymmetric severity of diabetic retinopathy in Waardenburg syndrome: response to authors
}

This article was published in the following Dove Press journal:

Clinical Ophthalmology

20 March 2012

Number of times this article has been viewed

\section{Aditi Gupta \\ Rajiv Raman \\ Tarun Sharma}

Shri Bhagwan Mahavir Department of Vitreoretinal Services,

Sankara Nethralaya, Chennai,

Tamil Nadu, India
Correspondence: Aditi Gupta Shri Bhagwan Mahavir Department of Vitreoretinal Services, Sankara Nethralaya, I8 College Road, Chennai 600006 ,

Tamil Nadu, India

Tel $+9 \mid 442827$ I6I6

Fax +9| 4428254180

Email guptaaditi_dr@yahoo.com
We read with great interest the recent article by Kashima et al, ${ }^{1}$ in which the authors report a case of asymmetric severity of diabetic retinopathy in Waardenburg syndrome. We want to highlight some concerns regarding this report. Previous reports have described many systemic and local factors associated with the development of asymmetric diabetic retinopathy. ${ }^{2,3}$ These include myopia $\geq 5 \mathrm{D}$, anisometropia $>1 \mathrm{D}$, amblyopia, unilateral elevated intraocular pressure, complete posterior vitreous detachment, unilateral carotid artery stenosis, ocular ischemic syndrome, and chorioretinal scarring. ${ }^{2,3}$ In any suspected case of asymmetric diabetic retinopathy, it is prudent to rule out the abovementioned factors first. In the present case, although the authors clearly mention the absence of internal carotid and ophthalmic artery obstruction on magnetic resonance angiography, it would have been more informative if the authors had also provided the refractive error, intraocular pressure, and posterior vitreous detachment status of both the eyes.

Likewise, it would have been useful to note the arm-retina time and retinal arteriovenous filling time in both the eyes on fundus fluorescein angiography, which is usually used to diagnose ocular ischemic syndrome by monitoring extension of the retinal circulation time, including time of blood circulation from the arm to the retina and the retinal arteriovenous filling time. ${ }^{4,5}$ The mere absence of internal carotid obstruction on magnetic resonance angiography cannot rule out the presence of ocular ischemic syndrome because, rarely, ocular ischemic syndrome can also occur secondary to other causes, such as arteritis. ${ }^{6,7}$ Comparing the arm-retina time and retinal arteriovenous filling time on fundus fluorescein angiography in both the eyes would be more helpful to rule out ocular ischemic syndrome.

Kashima et al report the presence of more advanced diabetic retinopathy in the eye with sectoral iris hypochromia than the eye in which iris hypochromia was total. ${ }^{1}$ Presence of asymmetric diabetic retinopathy in association with iris heterochromia has been reported earlier in Fuchs' heterochromic cyclitis, in which the affected eye (hypochromic iris) had nonproliferative diabetic retinopathy and the fellow eye had peripheral diabetic retinopathy. ${ }^{8}$ Although the authors hypothesized that Fuchs' heterochromic cyclitis protected the affected eye from progression to peripheral diabetic retinopathy, they could not find a clear mechanism for the same. ${ }^{8}$ The cases reported by Kashima et $\mathrm{al}^{1}$ and Murray et $\mathrm{l}^{8}$ bear similarities, and may suggest a common link in understanding the pathogenesis behind asymmetric severity of diabetic retinopathy. 
Further, asymmetric diabetic retinopathy has been defined as proliferative diabetic retinopathy in one eye and nonproliferative diabetic retinopathy or no retinopathy in the fellow eye, persisting for at least two years. ${ }^{2}$ Duker et al defined it as the presence of proliferative diabetic retinopathy with high-risk characteristics in one eye, with neither proliferative nor preproliferative changes in the opposite eye. ${ }^{9}$ Other authors have also defined asymmetric diabetic retinopathy as proliferative diabetic retinopathy in one eye and nonproliferative diabetic retinopathy in the other eye. ${ }^{10} \mathrm{In}$ the present case, the patient had proliferative diabetic retinopathy in both eyes with the presence of a huge neovascularization in the right eye and a tiny neovascularization in the left eye. Use of the term "asymmetric diabetic retinopathy" in this patient, as the authors have done in the discussion section, may not be correct using any definition of asymmetric diabetic retinopathy. Asymmetric diabetic retinopathy is a rare disease. We conducted a population-based study in south India (SN-DREAMS 1), in which 1414 subjects with type 2 diabetes were analyzed for the presence of diabetic retinopathy. ${ }^{11}$ Of 1414 subjects, diabetic retinopathy was present in 255 (18\%), and asymmetric diabetic retinopathy ${ }^{2}$ in only two $(0.14 \%)$.

In addition, the authors speculate that hypopigmentation of the fundus in Waardenburg syndrome may be responsible for the reduction in retinal metabolism, which led to a reduction in oxygen consumption and prevented further aggravation of diabetic retinopathy, as occurs in retinitis pigmentosa. ${ }^{1}$ It is known that hypopigmentary changes in the retina protect against diabetic retinopathy, but Smith et al reported the presence of diabetic retinopathy in a patient with loss of retinal pigmentation and speculated that the retinal dystrophy associated with A3243G does not prevent the development of diabetic retinopathy. ${ }^{12}$ Hence, there might be other mechanisms involved in the varied severity of diabetic retinopathy in subjects with hypopigmented fundi. Genetic analysis of such cases might bring more insight regarding this. 


\section{Response to letter to the editor}

\author{
Tomoyuki Kashima \\ Hideo Akiyama \\ Shoji Kishi
}

Department of Ophthalmology, Gunma University School of Medicine, Gunma, Japan

Correspondence: Tomoyuki Kashima

Department of Ophthalmology,

Gunma University School of Medicine,

3-39-15 Showamachi, Maebashi,

Gunma 37I-85II, Japan

Tel +81272208338

Fax +8I 53220384 I

Email kasimatomoyuki@yahoo.co.jp

Thank you for providing the opportunity to show more detailed data on this issue. The myopia in both of the patient's eyes was the same at $-4.5 \mathrm{D}$. Astigmatism was $-1.75 \mathrm{D}$ in the right eye and $-0.5 \mathrm{D}$ in the left eye. The intraocular pressure in both eyes was $13 \mathrm{mmHg}$, measured by noncontact tonometer, respectively. There was no posterior vitreous detachment seen in either eye, and we are sure that the authors suspected no posterior vitreous detachment because no neovascularization developed in either eye in this patient. The clinical condition was almost the same in both eyes.

As the authors of this letter stated, comparing both eyes for arm-retina time and retinal arteriovenous filling time on fundus fluorescein angiography may be helpful. Actually, the filling time of the right eye was normal (20.4 seconds). However, measuring these times in both eyes is not an easy task in most clinics because the patient must visit the clinic twice only, just for these measurements, which is unacceptable from the points of view of money and time. In addition, the systemic condition of patients with diabetes is usually not good for angiography, so we think the comments of these authors are clinically inappropriate.

Clinical Ophthalmology

\section{Publish your work in this journal}

Clinical Ophthalmology is an international, peer-reviewed journal covering all subspecialties within ophthalmology. Key topics include: Optometry; Visual science; Pharmacology and drug therapy in eye diseases; Basic Sciences; Primary and Secondary eye care; Patient Safety and Quality of Care Improvements. This journal is indexed on
The authors of this letter also said that Duker defined this condition as the presence of peripheral diabetic retinopathy with high-risk characteristics in one eye, with neither proliferative nor preproliferative changes in the opposite eye. However, Duker et $\mathrm{al}^{9}$ when defining it for their study, never proposed a definition of asymmetric peripheral diabetic retinopathy. In our case, clearly the width of neovascularization in both fundi were different, which was proven by fluorescein angiography.

\section{References}

1. Kashima T, Akiyama H, Kishi S.Asymmetric severity of diabetic retinopathy in Waardenburg syndrome. Clin Ophthalmol. 2011;5:1717-1720.

2. Browning DJ, Flynn HW Jr, Blankenship GW. Asymmetric retinopathy in patients with diabetes mellitus. Am J Ophthalmol. 1988;105:584-589.

3. Scialdone A, Menchini U, Pietroni C, Brancato R. Unilateral proliferative diabetic retinopathy and uveitis in the fellow eye: report of a case. Ann Ophthalmol. 1991;23:259-261.

4. Brown GC, Magargal LE. The ocular ischemic syndrome: Clinical, fluorescein angiographic and carotid angiographic features. Int Ophthalmol. 1988;11:239-251.

5. Kerty E, Eide N, Hørven I. Ocular hemodynamic changes in patients with high-grade carotid occlusive disease and development of chronic ocular ischaemia. II. Clinical findings. Acta Ophthalmol Scand. 1995;73:72-76.

6. Koz OG, Ates A, Numan Alp M, Gultan E, Karaaslan Y, Kural G. Bilateral ocular ischemic syndrome as an initial manifestation of Takayasu's arteritis associated with carotid steal syndrome. Rheumatol Int. 2007;27:299-302.

7. Hamed LM, Guy JR, Moster ML, Bosley T. Giant cell arteritis in the ocular ischemic syndrome. Am J Ophthalmol. 1992;113:702-705.

8. Murray DC, Sung VC, Headon MP. Asymmetric diabetic retinopathy associated with Fuch's heterochromic cyclitis. Br J Ophthalmol. 1999; 83:988-989.

9. Duker JS, Brown GC, Bosley TM, Colt CA, Reber R. Asymmetric proliferative diabetic retinopathy and carotid artery disease. Ophthalmology. 1990;97:869-874.

10. Valone JA Jr, McMeel JW, Franks EP. Unilateral proliferative diabetic retinopathy. I. Initial findings. Arch Ophthalmol. 1981;99:1357-1361.

11. Agarwal S, Raman R, Paul PG, et al. Sankara Nethralaya-Diabetic Retinopathy Epidemiology and Molecular Genetic Study (SN-DREAMS 1): study design and research methodology. Ophthalmic Epidemiol. 2005; 12:143-153.

12. Smith PR, Bain SC, Good PA, et al. Pigmentary retinal dystrophy and the syndrome of maternally inherited diabetes and deafness caused by the mitochondrial DNA 3243 tRNA(Leu) A to G mutation. Ophthalmology. 1999; 106:1101-1108

\section{Dovepress}

PubMed Central and CAS, and is the official journal of The Society of Clinical Ophthalmology (SCO). The manuscript management system is completely online and includes a very quick and fair peer-review system, which is all easy to use. Visit http://www.dovepress.com/ testimonials.php to read real quotes from published authors. 